\title{
Schumpeter e o Desenvolvimento Tecnológico: uma visão aplicada às Pequenas e Médias Empresas (PMES)
}

\author{
Marcus Vinicius de Oliveira Brasil ${ }^{1}$ \\ Cláudio André Gondim Nogueira ${ }^{2}$ \\ Sérgio Henrique Arruda Cavalcante Forte ${ }^{3}$
}

\section{Resumo}

A Teoria Schumpeteriana considera que quanto maiores forem as empresas em um determinado mercado, maior será a competição existente, pois as grandes empresas possuem uma maior capacidade inovadora e de resistência em relação às pequenas, já que entre as grandes o ritmo de introdução de inovações seria mais intenso. Entretanto, faz-se necessário considerar com mais ênfase a capacidade inovadora das Pequenas e Médias Empresas (PMEs). Assim, a questão fundamental para essas empresas está vinculada à capacidade delas aproveitarem as novas oportunidades que o mercado oferece, dos recursos que dispõem ou desenvolvem, das potenciais parcerias que poderiam firmar, bem como das suas ligações com instituições de pesquisa. Portanto, o objetivo principal deste ensaio é apresentar a Teoria Schumpeteriana sobre o desenvolvimento tecnológico, mostrando-a como uma abordagem fundamental para se compreender as estratégias inovadoras das empresas de maior porte, mas cujos princípios básicos também se aplicam às empresas de menor porte. Nas considerações finais apresenta-se que a inovação tecnológica preconizada por Schumpeter, além de ser um instrumento fundamental para o desenvolvimento e crescimento econômico pode impulsionar a concorrência entre as grandes e, também, entre as menores empresas, que podem ainda propiciar parcerias fazendo surgir um relacionamento ganha-ganha.

Palavras-chave: Inovação. Schumpeter. PME. Competição.

\footnotetext{
${ }^{1}$ Doutorando em Administração pela Universidade de Fortaleza - UNIFOR. End.: Rua Cândido Jucá, 123, Rodolfo Teófilo, Fortaleza-CE. CEP: 60430-580-Brasil.E-mail: mvobrasil@ufc.br.

${ }^{2}$ Doutorando em Administração pela Universidade de Fortaleza - UNIFOR. End.: Rua Oliveira Viana 452, Vicente Pinzon, Fortaleza-CE. CEP:60181-255-Brasil.E-mail: claudioandre@unifor.br.

${ }^{3}$ Doutor em Administração de Empresas pela Fundação Getulio Vargas - FGV/SP. Professor titular da Universidade de Fortaleza - UNIFOR. End.: Rua Tibúrcio Cavalcante, 847, apto 1901, Salinas, Fortaleza-CE. CEP:60125-100-Brasil. E-mail: sergioforte@unifor.br.

Artigo recebido em: 15/11/2010. Aceito em: 28/12/2010. Membro do Corpo Editorial Científico responsável pelo processo editorial: Rolando Juan Soliz Estrada.
}

Esta obra está sob a Licença Creative Commons Atribuição-Uso. 


\section{Introdução}

A tecnologia e seus vários aspectos foram e são cada vez mais abordados pelas diversas teorias econômicas. Todavia, deve-se ressaltar que um dos primeiros economistas a identificá-la como um aspecto fundamental para a compreensão do sistema capitalista e a formular toda uma teoria na qual ela desempenha um papel central foi Schumpeter. A sua análise serviu de base para teorias posteriores e colocou vários de seus questionamentos no centro da problemática tratada pela Ciência Econômica (KUPFER; HASENCLEVER, 2002; PAULA; CERQUEIRA; ALBUQUERQUE, 2001; COLARES, 1995; SOUZA, 1993).

A Teoria Schumpeteriana, mesmo tendo sido desenvolvida ao longo da primeira metade do Século XX, continua a ser atual, com algumas ressalvas, apesar das diversas mudanças que o sistema capitalista vem passando ao longo tempo, principalmente quando se intensificou o processo de globalização da economia mundial (KUPFER; HASENCLEVER, 2002; PAULA; CERQUEIRA; ALBUQUERQUE, 2001; COLARES, 1995; SOUZA, 1993).

Para Schumpeter (1988), uma pessoa que sonha ou deseja criar empresas, bem como participar da fundação delas e praticar a inovação, tem o caráter do empresário que realiza novas combinações, mas que o perde, assim que tem montado o seu negócio e começa a dirigi-lo. Pode ser um dos empregados na liderança de uma empresa, como gerentes ou membros da diretoria, ou mesmo um homem de negócios independente, como um financista. Pode ser um capitalista, especialmente em empresas pequenas.

A Teoria Schumpeteriana, em geral, constitui-se em um instrumental teórico consistente no que diz respeito à compreensão de como se dá o processo de concorrência industrial e de inovação tecnológica, que são aspectos importantes para a compreensão de como as empresas se organizam para produzir em uma economia capitalista (KUPFER; HASENCLEVER, 2002; COLARES, 1995; SOUZA, 1993; SILVA, 1984).

Como será mais detalhada adiante, a Teoria Schumpeteriana considera que quanto maiores forem as empresas em um determinado mercado, maior será a competição existente, pois, as grandes empresas possuem uma maior capacidade inovadora e de resistência em relação às pequenas, já que entre elas o ritmo de introdução de inovações seria mais intenso (SCHUMPETER, 1984; COLARES, 1995; SOUZA, 1993; SILVA, 1984). 
Entretanto, no atual contexto da economia mundial, marcada pela crescente globalização das atividades econômicas e por um processo intenso de inovações, faz-se necessário considerar com mais ênfase a capacidade inovadora das Pequenas e Médias Empresas (PMEs). As suas estruturas produtivas menores e mais flexíveis podem, em alguns contextos, favorecer as inovações, apesar delas comumente terem recursos limitados para as atividades de pesquisa e desenvolvimento e de estarem expostas a um maior nível de risco em relação às empresas maiores (MOMPO; REDOLI, 2009).

Portanto, a questão de pesquisa deste ensaio é a seguinte: é possível adaptar os preceitos da Teoria Schumpeteriana para as Pequenas e Médias Empresas (PMEs)?

Na tentativa de dar uma resposta a essa pergunta, este trabalho tem como objetivo apresentar a Teoria Schumpeteriana sobre o desenvolvimento tecnológico, mostrando-a como uma abordagem fundamental para se compreender as estratégias inovadoras das empresas de maior porte, mas cujos princípios básicos também se aplicam às empresas de menor porte.

Primeiramente, tratar-se-á da Teoria Schumpeteriana no que diz respeito à organização industrial, destacando o papel que as inovações, sobretudo as tecnológicas, trazem para a competitividade das empresas Logo em seguida, serão feitas algumas considerações acerca do desenvolvimento tecnológico, mostrando a sua relevância para o entendimento da concorrência entre as empresas. Mais adiante, será feita uma abordagem da questão das inovações estratégicas nas Pequenas e Médias Empresas (PMEs), em que se procurará mostrar como esse tipo de empresa se diferencia das grandes empresas, tentando evidenciar a importância que as inovações tecnológicas e a concorrência tem para elas. Posteriormente, será apresentada as considerações finais deste ensaio e, finalmente, as referências utilizadas.

\section{A Concorrência Schumpeteriana e o Processo de Inovação Tecnológica}

Segundo Camargo Neto (1993), na visão schumpeteriana, a concorrência que efetivamente tem lugar em uma economia capitalista não é aquela que se processa entre pequenas empresas produtoras de um mesmo produto homogêneo, mas a que se trava entre as empresas que buscam acima de tudo a inovação, sobretudo, a inovação tecnológica. 
Realmente, Schumpeter afirmava que a maioria dos economistas neoclássicos apenas se preocupava com a concorrência de preços, já que, para ele, a verdadeira concorrência é aquela baseada na busca incessante por vantagens de custo e por uma melhor qualidade dos produtos, sendo a inovação a mola fundamental que a impulsiona (KUPFER; HASENCLEVER, 2002; COLARES, 1995; CAMARGO NETO, 1993).

Segundo Silva (1984), Schumpeter foi um dos primeiros economistas a formalizar uma definição de inovação a partir da noção de função de produção. A sua preocupação básica estava mais restrita às grandes inovações (inovações primárias), inovações estas que alteravam substancialmente a função de produção, enquanto as pequenas inovações (inovações secundárias), ou seja, aquelas ocorridas em uma dada função de produção eram para ele menos relevantes para se compreender o processo de destruição criadora.

De acordo com Schumpeter (1988), Silva (1984), Souza (1993), Colares (1995) existem basicamente cinco tipos de inovações, são elas: a) o lançamento de um novo produto; b) a descoberta de novos métodos de produção; c) a abertura de novos mercados no país ou no exterior; d) a conquista de novas fontes de suprimento de insumos; e e) a instalação de novas formas de organização do mercado, como um novo monopólio ou a fragmentação de uma posição de monopólio.

Deve-se salientar que, dentre esses tipos de inovações citados, os dois primeiros são sem dúvida os tipos mais relevantes para a Teoria Schumpeteriana, por provocarem deslocamentos altamente relevantes na função de produção. Essas são as chamadas inovações tecnológicas (SILVA, 1984).

Existem diversas teorias que procuram explicar como se dá o processo de inovação tecnológica. Para a Teoria Neoclássica Ortodoxa, as inovações seriam deslocamentos ocorridos na função de produção decorrentes das atividades de Pesquisa \& Desenvolvimento (P\&D), exógenas ao sistema econômico, e cuja adoção estaria subordinada ao comportamento maximizador dos agentes econômicos. Contrariamente, para Schumpeter, o processo de inovação tecnológica seria basicamente endógeno ao sistema econômico e ocorreria em três fases distintas, mas complementares, que são as seguintes: a) Invenção; b) Inovação; e c) Difusão (KUPFER; HASENCLEVER, 2002; COLARES, 1995; SOUZA, 1993).

Primeiramente, a fase de invenção se dá quando novos produtos e ou processos produtivos são criados. À medida que essas inovações tecnológicas são introduzidas no sistema econômico, então, ocorre a fase de inovação pro- 
priamente dita. Quando o empresário empreendedor adota uma inovação tecnológica, ele obtém um diferencial competitivo, que se dá principalmente sob a forma de reduções dos seus custos de produção e ou de diferenciação de produtos, em relação às demais empresas concorrentes de um determinado mercado, o que lhe confere uma maior autonomia para determinar os seus preços. E isso acontece de acordo com a natureza da inovação introduzida (KUPFER; HASENCLEVER, 2002; COLARES, 1995; SOUZA, 1993).

Assim, as empresas concorrentes buscam reverter essa situação desfavorável, por meio da tentativa de desenvolver novas tecnologias ou de lançar novos produtos, ou seja, com a tentativa de copiar as criações desenvolvidas pela empresa inovadora. Entretanto, deve-se ressaltar que nem todas as empresas concorrentes são capazes de acompanhar o ritmo do processo de criação das empresas inovadoras. Portanto, os mecanismos de mercado abordados nesta análise, que delineiam a concorrência schumpeteriana, atuam para selecionar as empresas mais eficientes e mais lucrativas, expulsando os competidores que utilizam processos antigos e menos eficientes, ou seja, esse é basicamente um processo no qual resultam vencedores e perdedores (KUPFER; HASENCLEVER, 2002; COLARES, 1995; SOUZA, 1993).

Entretanto, isso não impede, todavia, que as inovações disseminem-se pelo sistema econômico e, quando isso finalmente acontece, considera-se que houve a fase de difusão, encerrando o processo de inovação tecnológica. Entretanto, vale salientar que, como a Teoria Schumpeteriana é essencialmente dinâmica, esse processo como um todo é contínuo ao longo do tempo, isto é, estão sempre surgindo novos produtos e novos processos de produção que reinauguram o ciclo descrito anteriormente, embora haja períodos em que isso ocorra com maior ou menor intensidade (KUPFER; HASENCLEVER, 2002; COLARES, 1995; SOUZA, 1993).

O processo schumpeteriano de inovação (tecnológica ou não) está intrinsecamente ligado à análise das estruturas de mercado capitalistas. Essa proposição se torna mais clara quando se atenta para o fato de que, quando o empresário adota uma inovação,

[...] ele tentará, durante o maior intervalo de tempo possível, reter o usufruto dos resultados alcançados, usando, para isso, à guisa de salvaguardas, patentes, segredos industriais, cláusulas preventivas em contratos de longo prazo etc. Antes que a inovação venha a se difundir, ela será monopolizada pelo empresário, que obterá lucros extraor- 
dinários em função do monopólio que detém. Trata-se de um monopólio temporário - distinto daquele contemplado pela teoria neoclássica - que normalmente desaparece com a difusão da inovação. Este monopólio é, pois, um resultado da concorrência, não se constituindo numa negação dela (CAMARGO NETO, 1993, p. 12).

O poder de monopólio sobre a inovação e a adoção de práticas restritivas à concorrência, já mencionadas, além de atuarem como uma vantagem competitiva para as empresas inovadoras em relação às concorrentes, conforme foi descrito anteriormente, restringem a entrada de novas empresas no mercado (KUPFER; HASENCLEVER, 2002). Para Schumpeter, essas "barreiras à entrada" se justificam pelo fato de elas influírem decisivamente sobre as decisões de investimento dos empresários, que somente estarão dispostos a investir em longo prazo se tiverem a expectativa de que obterão um retorno favorável para os seus investimentos, ou seja, faz-se necessária a existência desse período de estabilidade temporária para que sejam absorvidos os resultados decorrentes da inovação (CAMARGO NETO, 1993).

Entretanto, em conformidade com o que foi explicado anteriormente, vale salientar que a atitude das empresas concorrentes (existentes ou potenciais) diante dessa situação não é passiva, muito pelo contrário. Assim, em cada tentativa por parte dos empresários de reter os frutos advindos da introdução de inovações, a concorrência se tornará cada vez maior e não o contrário como se poderia supor, uma vez que os concorrentes serão impelidos a procurar formas de anular os efeitos que lhes são maléficos, no que diz respeito à sua participação no mercado. Dessa forma, à medida que o tamanho das empresas de um determinado mercado aumenta, a concorrência entre elas também se tornará maior, haja vista que Schumpeter considera que as grandes empresas possuem uma maior capacidade inovadora e uma maior capacidade de resistência em relação às pequenas, pois, entre as grandes o ritmo de introdução de inovações seria mais intenso (SCHUMPETER, 1984; KUPFER; HASENCLEVER, 2002; COLARES, 1995).

Essa concepção é, contudo, divergente dos economistas neoclássicos, pois, para eles, quanto maiores forem as empresas, menos dinâmico será o mercado e menor será a concorrência existente entre as empresas que o compõem, devido à sua crescente oligopolização (KUPFER; HASENCLEVER, 2002). 


\section{O Desenvolvimento Tecnológico}

De acordo com o apresentado até o momento, argumenta-se que a Teoria Schumpeteriana considera que o processo de inovação tecnológica está intrinsecamente relacionado às formas de concorrência industrial em vigor, o que remete a um conceito mais abrangente que é o de progresso técnico ou desenvolvimento tecnológico.

O progresso técnico condiciona as estratégias de crescimento adotadas pelas empresas, pois, de acordo com as formas de concorrência que caracterizam os mercados nos quais elas atuam é que elas podem utilizar eficazmente as inovações tecnológicas como instrumento de concorrência.

A Teoria Schumpeteriana considera, portanto, que o progresso técnico é essencialmente endógeno à estrutura industrial. Isso significa que as inovações ocorrem prioritariamente no interior da própria indústria, ou seja, quando as empresas dessa indústria são capazes de influir no curso e no ritmo do progresso, como é o que acontece na indústria eletrônica, por exemplo (KUPFER; HASENCLEVER, 2002). Segundo Araújo Jr. (1985, p. 18),

[...] nestas indústrias produtoras de inovações, o poder de comando de algumas empresas sobre a direção e a cadência do progresso técnico consiste no mecanismo primordial de preservação de suas parcelas de mercado.

Entretanto, deve-se ressaltar que, em alguns ramos da indústria, o progresso técnico é basicamente exógeno, como supunham os economistas neoclássicos. Isso acontece quando as inovações se dão prioritariamente em outros ramos da indústria, como é o caso da indústria têxtil, por exemplo, cujo desenvolvimento tecnológico depende bastante das inovações criadas pelas indústrias de máquinas e equipamentos e química (ARAÚJO Jr., 1985; PAVITT, 1984 apud PAULA; CERQUEIRA; ALBUQUERQUE, 2001).

Vale salientar que a constatação feita anteriormente, que diz respeito à exogeneidade do progresso técnico em alguns ramos da indústria, não modifica significativamente o conceito de concorrência discutido até o presente momento. $\mathrm{O}$ argumento central permanece o mesmo, isto é, que as empresas devem introduzir inovações, sobretudo as tecnológicas, para obterem vantagens competitivas em relação aos seus concorrentes e assim assegurar a sua sobrevivência no mercado em longo prazo. Apenas deve-se considerar que, 
nas indústrias cujo progresso técnico é exógeno, a preocupação básica do empresário empreendedor deve ser a de estar sempre bem informado acerca das inovações que surgem a cada momento nos demais ramos da indústria $e$ identificar aquelas que possam melhorar a eficiência produtiva de sua empresa ou a qualidade dos seus produtos e, em alguns casos, até mesmo que as vantagens advindas dessas inovações possam ser anuladas rapidamente pelas empresas concorrentes (ARAÚJO Jr., 1985; PAVITT, 1984 apud PAULA, CERQUEIRA; ALBUQUERQUE, 2001).

Enquanto isso, nas indústrias cujo progresso técnico é endógeno, a preocupação básica do empresário deve ser basicamente a de criar novas tecnologias mediante elevados investimentos nas atividades de pesquisa $e$ desenvolvimento (P\&D) e também na melhoria crescente da qualificação da mão de obra por ele utilizada, isto é, nos investimentos em capital humano (NOGUEIRA, 2007; ARAÚJO Jr., 1985; PAVITT; 1984 apud PAULA; CERQUEIRA; ALBUQUERQUE, 2001).

Com base nas discussões feitas anteriormente, é possível considerar que a Teoria Schumpeteriana é um arcabouço teórico consistente e que permite, em grande parte, a compreensão do processo de concorrência industrial e de inovação tecnológica no capitalismo. Entretanto, a ênfase dessa teoria está na capacidade inovadora das grandes empresas (COLARES, 1995).

No caso, Schumpeter evidenciou que a existência de oligopólios e monopólios nas economias capitalistas mais avançadas não era apenas uma exceção à regra, mas sim a própria regra. Como argumenta Colares (1995, p. 10),

[...] ele reconhecia que as unidades de grande escala haviam se tornado os motores mais potentes na propulsão do progresso a que ele se referia e, especialmente, do crescimento em longo prazo da produção total.

Entretanto, a maior concentração dos mercados não provoca uma piora nos padrões de vida da classe trabalhadora como se pode supor, muito pelo contrário. Com a oligopolização da economia, passam a existir grandes aumentos na produtividade do trabalho, de tal forma que são necessárias cada vez menos horas de trabalho para que um trabalhador possa comprar uma determinada mercadoria (SCHUMPETER, 1984).

Apesar das empresas maiores terem mais recursos e, consequentemente, mais capacidade de investir na geração de novas tecnologias e de assumir 
riscos, há de se considerar que, no contexto de uma economia cada vez mais globalizada e permeada por crescentes ondas de inovação no âmbito da chamada terceira revolução industrial (NOGUEIRA, 1997), não é possível desconsiderar a capacidade inovadora das Pequenas e Médias Empresas (PMEs).

Como enfatizam Mompo e Redoli (2009, p. 57),

Especialmente nos anos recentes, a inovação se tornou um fator determinante da competitividade para todas as organizações, qualquer que seja a sua natureza ou tamanho. Para que pequenas e médias empresas sobrevivam, um objetivo fundamental seria deixar de lado a idéia de que apenas grandes organizações são capazes de conduzir atividades inovadoras.

Dessa forma, considerando-se a pergunta desta pesquisa, deseja-se verificar se os preceitos da Teoria Schumpeteriana de que as empresas, sob o comando de empresários empreendedores, são capazes de inovar para, mesmo que temporariamente, obter uma posição privilegiada no mercado, podese aplicar às PMEs. Assim, faz-se necessário analisar as suas capacidades e as estratégias de inovação, o que será feito a seguir.

\section{A Estratégia Inovadora e as Pequenas e Médias Empresas}

A Escola Empreendedora defendeu o argumento de que as organizações precisam de um líder visionário e criativo com amplos poderes, propício à inovação. Teve seus primeiros rudimentos pelas contribuições de economistas, sendo Schumpeter o mais preeminente. O empresário inovador deve estar atento para os ciclos tecnológicos, pois esses ciclos refletem as mudanças que ocorrem na economia, e, de uma maneira geral, são determinados pela inovação tecnológica em processos, produtos e serviços (MINTZBERG; AHLSTRAND; LAMPEL, 2000; SCHUMPETER, 1984).

Na concepção de Peng (2008, p. 150) "Empreendedorismo é a identificação e exploração de oportunidades não exploradas anteriormente". Esse autor considera que o termo está mais apropriado para Pequenas e Médias Empresas (PMEs), ou seja, empresas com menos de 500 funcionários, e cha- 
ma de empreendedorismo corporativo o termo para as empresas que excederem esse número.

A estratégia competitiva geral deve conter a estratégia de tecnologia e deve ser preocupação de pequenos e médios empreendedores. Porter (1990, p. 164) destaca o fato de que "[...] a estratégia de tecnologia é o método de uma empresa para o desenvolvimento e o uso de tecnologia". Ainda, segundo o autor (1990, p. 164),

[...] a estratégia de tecnologia deve abordar três questões gerais: as tecnologias a serem desenvolvidas; se a liderança tecnológica deve ser buscada nestas tecnologias; o papel do licenciamento de tecnologia.

Essas são algumas das questões a serem contempladas na estratégia, se é importante para a empresa ser líder de determinado segmento de mercado, quais as novas tecnologias que realmente devem ser aprofundadas ou pesquisadas, se a proteção dessas inovações está devidamente efetivada.

Na realidade, conciliar o uso de tecnologias avançadas e os recursos humanos bem treinados e capacitados torna-se essencial para a obtenção de vantagens na competição (NOGUEIRA, 1997; DAHLMAN, 1993). Vale salientar que, quanto mais funcionais forem esses recursos, mais a empresa necessitará de maiores ajustamentos e assimilações, de forma a romper até aspectos de sua cultura organizacional. Porter (1990, p. 154) afirma que "[...] cada atividade de valor emprega alguma tecnologia para combinar insumos adquiridos e recursos humanos com o objetivo de produzir algum produto final".

A criação de pequenas empresas de alta tecnologia pode ser classificada de maneira simplificada em: spin-offs, emulação de grandes empresas e de universidades ou instituições de pesquisas (FERRO; TORKOMIAN, 1988). O termo spin-offs refere-se às novas empresas cujos empreendedores deixaram as firmas onde trabalhavam para iniciar seus negócios no mesmo ramo de atividades, tornando-se concorrentes de suas empresas anteriores. A motivação desses empreendedores é baseada na perspectiva de mais autonomia e retorno financeiro, bem como poderem levar à frente seus projetos rejeitados nas grandes empresas.

As grandes empresas, geralmente, não têm a mesma flexibilidade das pequenas. A burocracia nas grandes empresas pode ser uma barreira para a inovação tecnológica, atingindo, principalmente, as atividades de Pesquisa 
\& Desenvolvimento (P\&D), pelo raciocínio economicista de valorizar o resultado de pesquisas somente no curto prazo. Então, torna-se interessante para essas empresas estimular o surgimento de pequenas empresas, que podem oferecer a terceirização de serviços especializados ou fornecer produtos, de acordo com a demanda específica dessas grandes empresas, possibilitando uma estrutura adhocratica mais voltada à criatividade e à inovação. Para a pequena empresa, existem inúmeras vantagens financeiras, podendo até ser controlada acionariamente pela empresa maior. De acordo com Brasil (2001, p. 6), outros pontos a serem observados são:

As redes de computadores propiciam às PMEs a participação nas economias de escala. A instabilidade da demanda, a política monetária mundial afetada pelos choques do petróleo, a segmentação da demanda, o processo de abertura comercial e econômica, a introdução das tecnologias da informação entraram em choque com modelo administrativo antigo das grandes corporações, que tinham custos fixos elevados e grande inflexibilidade dos processos, produtos e serviços, favorecendo as PMEs com custos fixos baixos e maior flexibilidade. As grandes empresas tiveram que se adaptar na nova economia, aparecendo então as fusões, os processos de downsizing, a descentralização da produção, a terceirização, dando-se maior importância à iniciativa empreendedora $e$ às novas tecnologias de informação. Mesmo assim, as grandes empresas continuam comandando o destino da economia, que se globalizou.

A criação de empresas, a partir de pessoas e de projetos de pesquisa ligados às universidades ou às instituições de pesquisa, é viabilizada pela formulação de um novo produto, serviço ou, ainda, uma nova forma de encarar o mercado, obtidos pelo resultado de pesquisas científicas.

Uma inovação tecnológica pode ser um motivo para a criação de um empreendimento. No entanto, a imitação das novas tecnologias é uma realidade não apenas do mercado de tecnologia. A administração empreendedora deve ser capaz de lançar a nova tecnologia no tempo certo, satisfazendo os anseios da sociedade e ou tentando mudar seus hábitos de consumo. Os riscos de uma inovação baseada em conhecimentos científicos e ou 
tecnológicos e ou qualquer outra fonte devem ser perfeitamente assumidos pelo empreendedor.

As inovações frequentemente implicam em um considerável investimento de P\&D. Coutinho (1992) e Dahlman (1993), por exemplo, argumentam que os investimentos em P\&D não podem ser efetuados sem que haja um cauteloso planejamento, devido às incertezas existentes, tanto as relacionadas com as flutuações dos mercados mundiais como as relacionadas com o risco de insucesso intrínseco a tais investimentos, e devido às necessidades crescentes de padronização tecnológica. Assim, devido à limitação de recursos, essa observação é ainda mais importante para as PMEs.

Nesse contexto, as patentes e as licenças de tecnologia são formas de proteger os empreendimentos, que inovam com uma tecnologia emergente. As patentes nem sempre impedem as imitações, podendo apenas assegurar a autoria da criação, mas, em geral, aumentam o grau de dificuldade para o concorrente copiar a nova tecnologia. A importância das patentes e das licenças de tecnologia cai à medida que essa nova tecnologia torna-se obsoleta. Segundo Possas (1999, p. 72),

[...] as patentes permitem que as condições de produção (incluindo os custos) das firmas que as detêm sejam únicas. O licenciamento de tecnologia implica algo semelhante, mas com certa subordinação tecnológica da firma adquirente com relação à que cede sua tecnologia.

Ainda conforme Possas (1999, p. 64), “[...] a possibilidade de não conseguir apropriar-se de ganhos diferenciais com a inovação é um fator que pode levar as empresas a se acautelarem e retardarem a inovação". A estratégia do empreendedor pode ser defensiva em casos em que os custos com a inovação sejam maiores do que o retorno dela, devido à imitação.

Os produtos que têm um ciclo de vida curto podem ensejar a necessidade de formação de uma aliança entre pequenas e médias empresas (PMEs) e grandes empresas, pois pode não haver outro meio para colocação desses produtos no mercado antes que eles venham à obsolescência (BATY, 1994).

As alianças e parcerias estimulam a colaboração, tendo sido uma forma de fortificar as pequenas e médias empresas diante de concorrentes tão fortes como as maiores do ramo, principalmente após o advento da globalização dos mercados e da internacionalização deles. De acordo com Morgan (1996, 
p. 361), "[...] as organizações podem evoluir através tanto da colaboração quanto da competição". Essa teoria pode tentar explicar tantos casos de parceria, bem como de alianças estratégicas. Segundo Possas (1999, p. 54), “[...] alianças podem ser feitas não apenas entre produtores rivais, mas também com usuários, empregados etc.". Parcerias e alianças tornam-se também necessárias, quando a cooperação entre os empreendimentos leva a um melhor assentamento das atividades, produção, distribuição e serviços após a venda. Conforme Oliveira (1991), as alianças estratégicas das empresas, de forma geral, apresentam os seguintes benefícios:

a) Ter acesso otimizado ao mercado e, principalmente, aos seus segmentos. Esse pode ser considerado o principal benefício, pois é no mercado que se consolida a vantagem competitiva de uma empresa.

b) Ter acesso otimizado a uma tecnologia necessária, o que pode proporcionar uma alavancagem operacional e de qualidade altamente interessante para a empresa.

c) Ter acesso otimizado ao capital, o que pode representar a sustentação de uma empresa para a entrada em um novo negócio.

d) Ter situações de economia de escala, o que pode proporcionar reduções nos custos e, portanto, consolidar preços mais competitivos.

O relacionamento entre uma grande empresa e uma pequena pode ser vantajoso para ambos os lados. A parceria pode ocorrer em vários níveis, que vão do licenciamento à fusão, do incentivo da pesquisa e desenvolvimento à copropriedade, e atingindo até as áreas de produção e marketing (BATY, 1994). Para uma empresa pequena e iniciante, fica difícil montar uma estrutura de vendas e propaganda relevante. Sendo, assim, o apoio de uma grande empresa pode facilitar sua inserção no mercado, principalmente pelo desconhecimento da marca da empresa emergente, visto que não somente as condições de preço e desempenho são suficientes para penetrar o mercado, mas também a certeza de que a empresa vendedora do produto não vai desaparecer. Além disso, o marketing de relacionamento da grande empresa pode abrir caminhos a determinados clientes, para essas pequenas empresas.

$\mathrm{Na}$ parceria estratégica entre grandes e pequenas empresas, o aporte de capital também pode ser decisivo para o sucesso da empresa iniciante. A escassez de recursos, nessa fase, pode ser suprida com uma parceria nos 
lucros, pagamento adiantado, adiantamento de remessas, taxa de transferência de tecnologia ou royalties pré-pagos, a colocação de produtos no canal de distribuição da grande empresa, a remuneração por desenvolvimento de pesquisa consultada ou patrocinada, além de uma maior credibilidade com a comunidade financeira, facilitando os financiamentos com os agentes financeiros (BATY, 1994).

Jiang, Li e Gao (2008) enumeram possíveis causas para o fracasso das alianças: poder de barganha e dependência, instabilidade estrutural e inércia etc. Entretanto, a literatura em estabilidade é escassa se comparada com a de instabilidade, justificando assim, a proposta dos autores de levantar preposições sobre o assunto. Com exceção dos casos em que as alianças terminam, porque foram cumpridos os objetivos outrora planejados, existem outros pontos a serem levados em conta para o sucesso de uma aliança estratégica, tais como: aprendizagem cooperativa e competitividade, comprometimento, seleção do parceiro, reputação etc. Ou seja, mesmo que haja sucesso financeiro na parceira se não houver estes fatores já mencionados, a aliança fracassará.

A grande empresa ganha com a flexibilidade e a eficácia da pequena, mesmo com a possibilidade de as grandes empresas serem mais bem estruturadas na área de $\mathrm{P} \& \mathrm{D}$ do que as pequenas empresas, elas não podem fazer tudo sozinhas. O trabalho conjunto traz vantagens óbvias e até mesmo tecnologias pesquisadas nas pequenas empresas, diferentes do foco das grandes organizações, e podem complementar alguma área deficiente na grande empresa, a custos mais baratos, constituindo-se uma forma mais viável de explorar novos mercados.

No entendimento de Baty (1994), poderia ser mais fácil para a maioria das grandes empresas adquirirem as menores, ao invés de firmar parceiras, no entanto, essa aquisição imediata, geralmente não funciona por alguns motivos: não saber onde anexar a empresa, a saída do líder empreendedor, a alteração de metas etc. No caso de aquisições, a integração é outro desafio, devendo ser consideradas questões na reestruturação desde controles financeiros até a integração total, tentando possibilitar economias de escala e de escopo.

É claro que a questão das competências centrais é um antecedente crítico para empresa adquirente ter sucesso na aquisição, maximizando as sinergias positivas e aproveitando o valor criado em ambientes industriais similares. 
Outra forma de parceria tecnológica que poderia ser extremamente importante para as PMEs seria por meio da utilização produtiva de conhecimentos científicos, que são oriundos das atividades de pesquisa básica que, por não possuírem objetivos especificamente comerciais, geralmente são realizadas por entidades governamentais (como as universidades) ou por entidades sem fins lucrativos. Essa visão está intrinsecamente ligada ao conceito de Sistema Nacional de Inovação (SNI).

Conforme Carleial (1997), Edquist (1997), Costa (1996) e Campos (2004), o SNI tem o mérito de salientar a importância que outros elementos além dos de mercado têm para a compreensão dos processos inovadores, tornando importante o ambiente de inserção da empresa bem como os elementos institucionais, isto é, parte-se do princípio que a empresa é o agente básico da inovação, mas que ela está contextualizada numa determinada estrutura de mercado, numa região ou país, com es-tratégias competitivas definidas, e que acumula, ao longo do tempo, experiências e co-nhecimentos.

Assim, as possibilidades de cada empresa desenvolver um comportamento inovador estão diretamente associadas aos mecanismos de aprendizado que ela utiliza. Tal comportamento passa a depender, também, da interação que a empresa tenha com outras organizações, tais como clientes, competidores, contratadores, universidades, laboratórios e agentes governamentais, consultores, pesquisadores etc., para ganhar, desenvolver e trocar vários tipos de conhecimentos, informações e outros recursos (CARLEIAL, 1997; EDQUIST, 1997; COSTA, 1996).

Dessa forma, pode-se dizer que um Sistema Nacional de Inovação seria o conjunto de instituições que, individual e conjuntamente, contribuem para o desenvolvimento e para a difusão das novas tecnologias, e que fornece uma estrutura pela qual os governos formam e implementam políticas que influenciam no processo de inovação (CARLEIAL, 1997; CAMPOS, 2004).

A base do sistema de inovação é o sistema produtivo e é dessa interação que se estimula a criatividade e se obtém, mediante os diferentes processos de aprendizado, a reestruturação da produção. Assim, a capacidade inovadora das empresas passa a depender da construção prévia de um aparato voltado para inovação, o que se torna realmente importante à medida que as empresas aprendem cada vez mais com informações que vêm de fora dela (CARLEIAL, 1997; CAMPOS, 2004).

Dessa forma, amplia-se também a relevância das ações governamentais na construção desse aparato voltado para a pesquisa. Certamente, quan- 
do bem organizado, o sistema nacional pode se constituir em um poderoso motor do progresso; desorganizado pode inibir seriamente o processo de inovação. O importante, porém, é destacar o cará-ter imprescindível da ação do Estado, quer como coordenador do Sistema quer como articulador da política econômica de longo prazo, notadamente a política industrial e tecnológica (CARLEIAL, 1997; CAMPOS, 2004).

Enfim, a constituição de um SNI tem como suposto uma interação mais significativa entre Ciência e Tecnologia, reconhecendo que as empresas passam a ganhar, à medida que a pesquisa básica progride, e isso não apenas para o caso de inovações radicais, mas também no caso de inovações incrementais, que são as mais habituais dentre as empresas, pertençam elas a qualquer setor e sejam elas de qualquer tamanho (CARLEIAL, 1997).

De posse dos conhecimentos apresentados até esse ponto é, então, possível perceber que tanto as empresas grandes como as pequenas e médias têm capacidade para inovar e essa capacidade varia de acordo com o contexto em que cada empresa se insere. Por exemplo, em ambientes com ricas parcerias e alianças entre empresas e outras instituições, apoiadas por um sistema nacional de inovação bem construído, as PMEs teriam uma capacidade inovadora maior, que seria favorecida por suas estruturas mais enxutas e dinâmicas. Em outros contextos, as grandes empresas provavelmente teriam mais a capacidade para inovar.

Mompo e Redoli (2009) argumentam que não só a capacidade, mas também a forma de inovar seja diferente numa comparação entre grandes, médias e pequenas empresas. E, a inovação não seria exclusiva para apenas um tamanho de firma. No caso, três situações básicas seriam possíveis:

a) A situação em que a empresa está satisfeita com a sua posição no mercado e consegue desenvolver os seus produtos por meio de inovações incrementais (ou secundárias como diria Schumpeter) de forma a manter os seus clientes satisfeitos.

b) A situação em que a empresa deseja crescer consideravelmente em seu mercado, fazendo-se necessário para tanto o desenvolvimento de novas tecnologias (inovações primárias) para que os consumidores percebam as mudanças nos produtos oferecidos.

c) A situação em que a empresa encontra-se com problemas em manter a sua participação e lucratividade em um mercado específico e estrategicamente se torna mais interessante mover-se para outros 
segmentos mediante inovações de mercado (que são inovações primárias, mas não necessariamente tecnológicas).

Para esses autores, a inovação tecnológica é importante para determinar a competitividade de uma empresa, mas a verdadeira questão seria quão inovadora a tecnologia deveria ser. Em alguns casos seriam suficientes pequenos ajustes nos produtos e processos para manter a empresa em uma posição desejável no mercado. Já em outros casos, em que a empresa pretende crescer consideravelmente, por exemplo, somente inovações tecnológicas relevantes seriam capazes de alavancar o seu desempenho da maneira desejada (MOMPO; REDOLI, 2009).

Mais especificamente, Mompo e Redoli (2009) consideram que as empresas maiores é que têm, em geral, mais capacidade para empreender grandes inovações tecnológicas devido à grande necessidade de recursos. Entretanto, em alguns casos, a dificuldade de inovar das PMEs devido à limitação de recursos financeiros pode ser reduzida consideravelmente, como foi argumentado antes quando, por exemplo, são possíveis as parcerias com outras empresas e instituições. Deve-se considerar também que em alguns setores de alta tecnologia as PMEs também podem ter ampla capacidade inovadora.

De fato, a inovação depende da indústria em consideração. No caso, nas indústrias que são mais intensivas em capital, as grandes empresas tendem a ser mais inovadoras, conforme foi previsto por Schumpeter. Já nas indústrias menos intensivas em capital, as empresas de menor porte são mais inovadoras. Essa foi a conclusão obtida por um estudo empreendido por Acs e Andretsch (1987 apud TABAKU; SALLAKU, 2008), que examinaram um grande painel de informações de países como Itália, Alemanha, França, Japão, Reino Unido e Estados Unidos, muito embora tenham sido identificadas várias diferenças nesses países no que diz respeito à postura empreendedora das empresas.

Os principais resultados do estudo de Acs e Andretsch (1987 apud TABAKU; SALLAKU, 2008) foram os seguintes:

a) Em indústrias menos intensivas em capital, as PMEs foram mais inovadoras em 156 indústrias (pouco mais de um terço do total) enquanto as grandes empresas foram mais inovadoras em 122 delas (ou em um pouco mais de um quarto do total).

b) Não existe uma diferença evidente na qualidade da inovação de empresas grandes ou pequenas, embora as grandes empresas te- 
nham introduzido um total de 2.608 inovações, já as menores introduziram 1.923 inovações no período pesquisado.

c) Deve-se considerar ainda que as empresas menores tenham aproximadamente a metade dos empregados das empresas maiores, fazendo com que as pequenas empresas tenham obtido 322 inovações por milhão de empregados ao passo que as grandes obtiveram 225 inovações por milhão de empregados.

Esses resultados podem ser complementados por evidências fornecidas por Chakrabarti e Halperin (1990 apud TABAKU; SALLAKU, 2008) de que as empresas de menor porte produzem mais inovações por dólar de pesquisa que as grandes empresas.

Ademais, mesmo em setores que as PMEs têm menor capacidade de gerar inovações tecnológicas muito relevantes, elas ainda têm ampla capacidade de empreender inovações de mercado, mais especificamente na parte comercial, dependendo da sua habilidade de identificar lacunas no mercado, conforme indicam Mompo e Redoli (2009). No caso, essas inovações comerciais seriam aquelas que fazem com que os produtos da empresa se tornem mais atrativos para os clientes ou que tornam a forma de distribuição dos produtos mais efetiva. Vale salientar que essas não seriam inovações tecnológicas propriamente ditas, mas sim inovações organizacionais, mas que podem favorecer ao crescimento das empresas no longo prazo.

Vale ressaltar, também, que a capacidade inovadora depende do setor em consideração. No caso, uma vez que a microeletrônica e a biotecnologia têm formado a base do paradigma científico e tecnológico dominante atualmente (NOGUEIRA, 1997; DAHLMAN, 1993; COUTINHO, 1992), abriu-se espaço para que algumas PMEs se tornassem altamente inovadoras em certos setores, especialmente nos menos intensivos em capital físico e mais intensivos em tecnologia e capital humano como é, por exemplo, o caso das empresas que já nascem globais. Nesses casos, as PMEs podem aproveitar as vantagens decorrentes de uma menor estrutura e maior flexibilidade. Já em setores que mais tradicionais ou intensivos em capital, de acordo com as evidências empíricas fornecidas pelo estudo de Acs e Andretsch (1987 apud TABAKU; SALLAKU, 2008), as grandes empresas tendem a levar vantagem.

Outra estratégia inovadora que pode favorecer às PMEs é a de inovar com base na imitação e ou na pequena diferenciação de produtos. Freeman (1994 apud PAULA, CERQUEIRA; ALBUQUERQUE, 2001), por exemplo, 
considerou que Schumpeter subestimou o esforço criativo envolvido na imitação e nas atividades de difusão tecnológica, dando muito ênfase às grandes inovações. No caso, o paradigma científico e tecnológico atual favorece essas inovações secundárias e, também, são capazes de conferir um maior poder de mercado para as PMEs mais inovadoras. Schumpeter possivelmente deu menos ênfase às inovações menores, pois, em sua época, predominavam as indústrias que fabricavam produtos padronizados e em série por meio de grandes linhas de montagem (NOGUEIRA, 2007).

Outras parcerias podem ser realizadas com organizações governamentais ou sem fins lucrativos, no escopo do que foi denominado de Sistema Nacional de Inovação (SNI). Nesse contexto, quando há um SNI bem organizado, a capacidade inovadora das PMEs pode aumentar consideravelmente na medida em que ocorrem desenvolvimentos na ciência básica. Em alguns países, a produção baseada em matérias-primas brutas é importante, em outros, a produção intensiva em conhecimento é mais dominante. Por essas e outras razões, os sistemas diferem quanto ao montante de recursos gastos em $\mathrm{P} \& \mathrm{D}$ e na inovação. Esses sistemas também podem diferir quanto aos seus desempenhos em termos de desenvolvimento tecnológico e difusão de conhecimentos (EDQUIST, 1997; CAMPOS, 2004). Por conta dessas considerações, pode-se elaborar o seguinte quadro comparativo entre as empresas maiores e menores (Quadro 1) da seguinte forma:

\begin{tabular}{|l|l|}
\hline \multicolumn{1}{|c|}{ Empresas Maiores } & \multicolumn{1}{c|}{ Empresas Menores } \\
\hline $\begin{array}{l}\text { Corporações grandes e maduras, forte poder } \\
\text { econômico. }\end{array}$ & $\begin{array}{l}\text { A importância das PMEs no mundo empre- } \\
\text { sarial, como elemento de flexibilidade da } \\
\text { economia. }\end{array}$ \\
\hline $\begin{array}{l}\text { Inovação tecnológica constante. Pesquisa e } \\
\text { Desenvolvimento. }\end{array}$ & Forte rede para inovação. \\
\hline $\begin{array}{l}\text { Grandes Oligopólios, algumas práticas } \\
\text { monopolístas. Associadas a grandes comple- } \\
\text { xos financeiros. }\end{array}$ & $\begin{array}{l}\text { Spin-offs: pessoas que passaram a ser con- } \\
\text { correntes das suas firmas anteriores. } \\
\text { Emulação de grandes empresas. } \\
\text { A criação de empresas a partir de pessoas, e } \\
\text { projetos de pesquisa ligados às universidades } \\
\text { ou instituições de pesquisa (FERRO; } \\
\text { TORKOMIAN, 1988). }\end{array}$ \\
\hline $\begin{array}{l}\text { As Tecnologias da Informacão e Comunicação } \\
\text { (TIC) são essenciais para a inovação. }\end{array}$ & $\begin{array}{l}\text { Muitos start-ups (criação de novas empresas) } \\
\text { em tecnologia são empresas que já nascem } \\
\text { globais. }\end{array}$ \\
\hline
\end{tabular}

Quadro 1: Comparação entre as Empresas Maiores e Menores

Fonte: Elaborado pelos autores 
Sendo assim, a abordagem schumpteriana é fundamental para se compreender as estratégias inovadoras das empresas de maior porte, mas seus princípios básicos também se aplicam às empresas de menor porte.

\section{Considerações Finais}

Como se pode perceber, a análise schumpeteriana busca mostrar a importância que a tecnologia desempenha na determinação da organização produtiva das empresas capitalistas, pois, é ela que confere dinamismo ao sistema e que define o padrão de concorrência entre as empresas nos diversos mercados de bens.

Este ensaio procurou discutir, com base na literatura especializada, se os preceitos da Teoria Schumpeteriana também poderiam ser aplicados às PMEs, isto é, se elas seriam capazes de obter vantagens competitivas por meio de suas estratégias de inovação.

Conforme foi discutido, a priori todas as empresas, independente do tamanho, podem inovar, mas que essa capacidade inovadora varia de acordo com contexto da própria empresa e com o ambiente ao qual ela se insere. Depende, também, da sua capacidade de definir boas estratégias de inovação.

No caso específico das PMEs, há de se considerar que, no contexto de uma economia mundial globalizada, há uma pressão crescente por parte da concorrência e dos competidores por produtos de melhor qualidade e por uma maior eficiência produtiva. Entretanto, devido ao seu tamanho, elas, em geral, possuem menos recursos financeiros, menos informação e estão mais susceptíveis ao risco do que as grandes empresas.

Por outro lado, isso não significa que as PMEs não podem adotar uma estratégia de inovação contínua em busca de vantagens competitivas nos mercados em que atuam, ou até que sejam capazes de desfazer grandes monopólios e oligopólios nos moldes definidos por Schumpeter. Tudo vai depender da situação em análise e dos diversos fatores (em muitos casos complementares) que afetam as suas estratégias de inovação.

Primeiramente, é fundamental a presença do empresário empreendedor, pois, para Schumpeter, ele é o agente que reúne cientistas, técnicos e capitais (que incluem tanto os montantes cedidos diretamente pelos capitalistas como os créditos fornecidos pelos banqueiros) para obter as novas combinações que são introduzidas no sistema econômico. É, pelo menos em par- 
te, a postura empreendedora da empresa que lhe permitirá adaptar ou até modificar o ambiente em que se insere, que definirá a sua capacidade de aproveitar as novas oportunidades que o mercado oferece, aproveitar os recursos existentes ou desenvolver os recursos de que necessita.

É importante mencionar que na época em que Schumpeter desenvolveu suas teorias, o paradigma científico e tecnológico era outro, quando predominavam grandes linhas de produção e em que os investimentos necessários para inovar eram muito elevados. Aliado à crescente oligopolização de vários setores, esse aspecto deve ter sido essencial para que ele desse maior ênfase na capacidade inovadora das grandes empresas.

Caso as condições do mercado não sejam tão favoráveis e ou se os custos de P\&D forem muito elevados, as PMEs poderão buscar fazer parcerias para inovar. Essas parcerias podem ser realizadas, por exemplo, com outras empresas, inclusive com empresas de maior porte. O objetivo é que, por meio da cooperação, as PMEs possam fortalecer sua capacidade inovadora e, consequentemente, a sua competitividade, para lhe dar um melhor posicionamento no mercado ou até para buscar outros mercados.

Então, com base no arcabouço teórico desenvolvido por Schumpeter e algumas contribuições de outros autores, principalmente dos chamados neoschupeterianos, foi possível analisar alguns pontos fundamentais acerca do comportamento inovador das PMEs em sua busca por um melhor posicionamento no mercado. No entanto, estudos adicionais poderiam ser efetuados com o intuito de aprofundar essa discussão considerando, por exemplo, outros fatores que afetam as estratégias inovadoras das PMEs, como se dá o processo de geração de novas tecnologias nas empresas de menor porte $e$, também, como os aspectos organizacionais e institucionais dão suporte (ou entravam) à definição de suas estratégias de inovação. Esses são temas para estudos futuros.

\section{Agradecimentos}

Agradecemos à Fundação Cearense de Apoio ao Desenvolvimento Científico e Tecnológico-FUNCAP. 


\section{Schumpeter and Technological Development: a vision applied to Small and Medium Enterprises}

\section{Abstract}

The Schumpeterian theory consider that larger enterprises acting in a given market will increment the competition, because large enterprises have a greater innovative capacity and resistance compared with the small enterprises, since between the larger ones the rhythm to introduce innovations would be more intense. However, it is necessary to consider more emphasis on the innovative capacity of Small and Medium Enterprises (SMEs). Thus, the key issue for these companies is linked to their technical ability to take advantage of new opportunities offered by the market, the resources they have or develop, the potential partnerships that could establish, as well as its links with research institutions under the National Information System. Therefore, the main goal of this work is to present the Schumpeterian theory of technological development as a fundamental approach to understanding the innovative strategies of larger firms, but whose basic principles also apply to smaller companies. It is concluded that the technological innovation proposed by Schumpeter, besides being a fundamental instrument for the development and economic growth can boost competition between large firms and smaller, but can also facilitate partnerships leading to a win-win relationship.

Key words: Innovation. Schumpeter. SME. Competition.

\section{Referências}

ARAÚJO JR., J. T. Tecnologia, concorrência e mudança estrutural: a experiência brasileira recente. São Paulo: IPEA, 1985.

BATY, G. B. Pequenas e médias empresas dos anos 90: guia do consultor e do empreendedor. Traduzido por Sandra Regina Garcia Palumbo. São Paulo: Makron Books, 1994.

BRASIL, M. V. de Oliveira. A nova economia e a internet. 2001. $57 \mathrm{f}$. Monografia (Especialização em Planejamento e Desenvolvimento Econômico) Faculdade de Economia, Administração, Atuária e Contabilidade, Universidade Federal do Ceará, Fortaleza. 
CAMARGO NETO, F. As metamorfoses conceituais da concorrência. Campinas: Cadernos da FACECA, v. 2, n. 2, p. 10-14, jul./dez., 1993.

CAMPOS, F. L.S. Inovação, tecnologia e alguns aspectos da análise neoschumpeteriana. Revista Eletrônica Administradores sem Fronteiras. São Paulo, v. 1, n. 1, 2004.

CARLEIAL, Liana Maria da Frota. Sistemas regionais de inovação (SRI) e relação entre firmas: As "pistas" para um formato de desenvolvimento regional. Revista Econômica do Nordeste, Fortaleza, v. 28, n. especial, p. 143-168, jul. 1997.

COLARES, J. F. A mudança econômica em Schumpeter. Fortaleza: CAEN/ UFC, 1995. (Texto para discussão n. 137).

COSTA, A. B. Tecnologia, reestruturação industrial e impactos socioeconômicos. Porto Alegre: UFRS, 1996. (Texto para discussão n. 96/07).

COUTINHO, L. A terceira revolução industrial e tecnológica: As grandes tendências de mudança. Economia \& Sociedade, Campinas, ago. 1992, p. 69-87.

DAHLMAN, C. Os países em desenvolvimento e a terceira revolução industrial. In: VELLOSO, J. P. R.; MARTINS, L. (Org.). A nova ordem mundial em questão. Rio de Janeiro: José Olympio, 1993, p. 259-290.

DUNCAN, C.; MTAR, M. Determinants of International Acquisition Success: Lessons from FirstGroup in North America. European Management Journal, v. 24, n. 6, p. 396-410, 2006.

EDQUIST, C. Systems of innovation approaches: their emergence and characteristics. In: EDQUIST, C. (Ed.) Systems of innovation. Londres: Puiter, 1997.

FERRO, J. R.; TORKOMIAN, A. L. V. A criação de pequenas empresas de alta tecnologia. Revista de Administração de Empresas, Rio de janeiro, v. 28, n. 2, p. 43-50, abr./jun. 1988.

JIANG, Xu; LI, Yuan; GAO, Shanxing. The stability of strategic alliances: characteristics, factors end stages. Journal of International Management, Philadelphia, n. 14, p. 173-189, 2008. 
KUPFER, D.; HASENCLEVER, L. Economia industrial: fundamentos teóricos e práticas no Brasil. Rio de Janeiro: Campus, 2002.

MOMPO, R.; REDOLI, J. Innovation strategies for small and medium-sizedenterprises. Innovation, v. 9, n. 1, p. 57-59, 2009.

MORGAN, G. Imagens da organização. São Paulo: Atlas, 1996.

MINTZBERG, H.; AHLSTRAND, B.; LAMPEL, J. Safári de Estratégia: um roteiro pela selva do planejamento estratégico. Traduzido por Nivaldo Montigelli Júnior. Porto Alegre: Bookman, 2000.

NOGUEIRA, C. A. G. A III revolução industrial e a importância dos investimentos em capital humano sobre a competitividade das empresas industriais. Congresso Brasileiro dos Economistas, 12. Fortaleza, 1997. Anais... Fortaleza: COFECON, 1997.

PAUlA, J. A.; CERQUeIRA, H. E. A. G.; AlBUQUERQUE, E. M. Ciência e tecnologia na dinâmica capitalista: a elaboração neo-schumpeteriana e a teoria do capital. Belo Horizonte: CEDEPLAR/UFMG, 2001. (Texto para discussão n. 152).

PENG, M. W. Estratégia Global. Traduzido por Vértice Translate. São Paulo: Thomson Learning, 2008.

PORTER, M. E. Vantagem competitiva: criando e sustentando um desempenho superior.Trad. Elizabeth Maria de Pinho Braga. Rio de Janeiro: Campus, 1990.

POSSAS, S. Concorrência e competitividade. São Paulo: Hucitec, 1999. SCHUMPETER, J. A. Capitalismo, socialismo e democracia. Rio de Janeiro: Zahar, 1984.

Teoria do desenvolvimento econômico: uma investigação sobre lucros, capital, crédito, juro e o ciclo econômico. Traduzido por Maria Sílvia Possas. 3. ed. São Paulo: Nova Cultural, 1988.

SILVA, M. Inovação tecnológica - um estudo de caso. São Paulo: IPEA/USP, 1984.

SOUZA, N. Desenvolvimento econômico. São Paulo: Atlas, 1993. 
TABAKU, J. ; SALLAKU, S. Small businesses, promoters of development, international evidence. MANAGEMENT OF INTERNATIONAL BUSINESS AND ECONOMIC SYSTEMS (MIBES). Larissa (Grécia), 2008. Anais... Larissa (Grécia): Technological Institute of Larissa, 2008. Disponível em: <http://mibes.teilar.gr/conferences/MMIBES_CD_2008/.../Tabaku-Sallaku.pdf > . Acesso em: 25 set. 2010. 